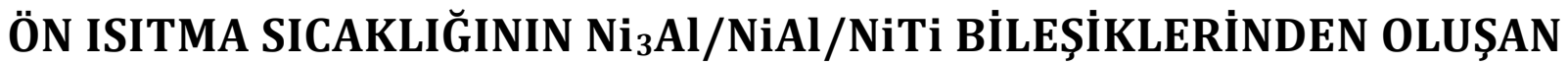 FONKSIYONEL DERECELENDİRILMISS MALZEMENIN YAPISINA ETKISIININN İNCELENMESİ
}

\section{INVESTIGATION OF PREHEAT TEMPRATURE EFFECT ON THE STURCTURE OF FUNCTIONALLY GRADED Ni 3 Al/NiAl/NiTi INTERMETALLIC COMPOUND}

\author{
Musa KILIÇ1*, Ihsan KIRIK², Bülent KURT³, Nuri ORHAN4
}

1İmalat Müh. Bölümü, Teknoloji Fakültesi, Batman Üniversitesi, Batman, Türkiye. musa_kilic21@hotmail.com

2Metalurji ve Malzeme Müh. Bölümü, Mimarlık ve Mühendislik Fakültesi, Batman Üniversitesi, Batman, Türkiye. ihsan.kirik@batman.edu.tr

${ }^{3}$ Metalurji ve Malzeme Müh. Bölümü, Mimarlık ve Mühendislik Fakültesi, Nevşehir Hacı Bektaş Veli Üniversitesi, Nevşehir, Türkiye. bkurt@nevsehir.edu.tr

${ }^{4}$ Metalurji ve Malzeme Müh. Bölümü, Teknoloji Fakültesi, Frrat Üniversitesi, Elazığ, Türkiye.

norhan@firat.edu.tr

$\ddot{0} \mathbf{z}$

Bu çalıșmada, Ni3Al/NiAl/NiTi bileșiklerinden olușan fonksiyonel derecelenmiş malzeme(FDM) kendi kendine ilerleyen yüksek sicaklık sentezlemesi (KKIYSS) tekniği ile üretilmiștir. Bu üç farklı bileșiği oluşturacak tozlar hassas bir șekilde tartıldıktan sonra mekanik olarak karıştırılmış ve $200 \mathrm{MPa}$ basınçla preslenmiştir. Preslenen numuneler, 200,300 ve $400{ }^{\circ} \mathrm{C}$ ön Isitma sicakllklarında yüksek voltajl tutușturma yöntemi (YVTY) ile argon gazı atmosferinde ateşlenerek üretimi gerçekleștirilmiștir. Üretilen bu fonksiyonel derecelenmiș malzemelerin mikroyapıları optik mikroskop, Taramalı Elektron Mikroskobu (SEM) ve X-Ișınları Kırınım Cihazı (XRD) ile incelenmiș. Sonuç olarak, KKIYSS yöntemi ile her üç ön ısıtma sıcaklığında da fonksiyonel derecelenmiş malzeme başarıla üretilmiş ve istenen metaller arası bileşikler elde edilmiş ancak arakesitlerde daha fazla ergime ve boșluk ile birlikte ana fazlar dışında fazların da oluștuğu görülmüştür.

Anahtar kelimeler: FDM, KKIYSS, NiTi, NiAl, Ön ısıtma sıcaklığı
Abstract

In this study, a functional graded material (FGM) consisted of NiTi NiAl and Ni3Al were manufactured by self-propagating high-temperature synthesis (SHS) technique. These three different compound powders were mixed in a rotating container after accurately weighed and cold compacted under $200 \mathrm{MPa}$ pressure. These pressed samples were produced for 200,300 and $400{ }^{\circ} \mathrm{C}$ preheating temperature by igniting with high voltage under argon gas atmosphere. The microstructures of these functional graded materials were examined by microscopy, Scanning Electron Microscopy (SEM) and X-Ray Diffraction (XRD). Consequently, functional graded material successful generated by SHS in every three preheating temperature and the metallic desired compounds were obtained but, it was seen that apart from the main phases in the intersection there are other phases with more melting and gaps.

Keywords: FGM, SHS, NiTi, NiAl, Preheating temperature

\section{Giriş}

Fonksiyonel dereceli malzemelerin, karakterizasyonu da dâhil olmak üzere, özellikleri ve üretim yöntemleri malzeme biliminin hızla gelișen yeni bir alanıdır. Bu yeni malzeme kavramı adezyonu artırmak ve yeniden kullanılabilir roket motorları için geliştirilmiş metal seramik kompozitlerdeki termal gerilmeleri en aza indirmek için önerilmiştir. Fonksiyonel dereceli malzemeler fikri Japonya'da 1980'lerin başında önemli ölçüde gelişmiştir. Japonya'da FDM alanında yapılmış olan ulusal program çerçevesinde çalışmalar 15 yıl boyunca sistematik olarak gerçekleştirilmiştir [1]-[3].

Fonksiyonel derecelendirilmiş malzemelerin en yaygın olarak bildirilen imalat yöntemleri: toz metalürjisi (T/M) infiltrasyon, döküm, plazma püskürtme, lazer kaplama, buhar çöktürme ve yanma sentezlenmesidir. Örneğin T/M, plazma püskürtme, lazer kaplama ve buhar biriktirme yöntemleri yoğun enerji ve pahalı ekipmanlar gerektirir. T/M süreçlerinde gözlenen başka bir sorun sicak presleme veya sicak izostatik presleme aşamasında oluşan katmanlı yapının bozulmasını içerir.
FDM'lerin imalatı için belki de en ilgi çekici olan yöntem KKIYSS yöntemidir. Yanma sentezlemesi FDM'lerin üretiminde hızl, ucuz ve güvenilir bir yöntem sunmaktadır.

Bu yöntemde gereken enerji ekonomik bir işlem yapmadan ve herhangi bir pahalı cihaz gerektirmeden bileşenleri arasında oluşan ekzotermik reaksiyon tarafından sağlanmaktadır [4],[5].

Reaksiyonla sentezleme (yanma sentezlemesi), ham ürünlerin, ateşlenir ateşlenmez ekzotermik bir reaksiyonla, bir anda istenen ürüne dönüştüğü işlemin adıdır. İşlem iki alt ateşleme yöntemine ayrılabilir. İlki, hacim yanma sentezi (HYS) ve ikincisi KKIYSS'dir. Bu sentezlemede, karıștırılan tozlardan üretilen bir briket (kompakt), bir ucundan bir tungsten bobin yardımı ile ateşlenir ve bu uçta başlayan reaksiyon bir dalga şeklinde ilerleyerek, tozların bir kısmını yakar geri kalanını da sıcaklığın etkisi ile ergitir ve nihai ürünü meydana getirir. Yanma sentezlenmesi $\mathrm{NiAl}_{-} \mathrm{Al}_{2} \mathrm{O}_{3}$ FDM ve TiC-NiAl FDM uygulamaları için kullanıldığı gibi, yoğun TiC-Ni FDM'ler üretmek ve isıl bariyer malzemesi olarak kullanmak $\mathrm{Ni}_{3} \mathrm{Al} / \mathrm{Al}_{2} \mathrm{O}_{3}+\mathrm{TiB}_{2}$ FDM sistemlerinin araştırılması için de 
kullanılmıștır [5]-[7]. Çok fonksiyonlu davranıș ve performansları nedeniyle FDM'ler; biyomedikal ve güç sektörlerinde, elektronik, savunma, otomotiv, havacillk sektörleri gibi geniş uygulama alanlarında yerini almıștır [8].

Zhang ve diğ. (1995) disk șeklinde üretmiș oldukları TiC-Ni3 AI fonksiyonel derecelendirilmiş malzemesinin termal gerilmeleri, bir eksenel simetrik sonlu elemanlar yöntemi kullanarak hesaplamışlardır. Yapmış oldukları test sonucunda termal genleşme katsayısı için sayısal sonuçların iyi uyum göstermiş olduklarını belirlemişlerdir. Fakat Young modülünün test değerlerinin hesaplanan değerlerden daha büyük olduğunu tespit etmişlerdir [9].

Lei ve diğ. 2004'te yapmış oldukları bir çalışmada Ni-Al sistemli fonksiyonel derecelendirilmiş malzemelerin SHS ile başarıyla üretilebileceğini, geleneksel sinterleme ile karşılaștırıldığında, lazer sinterlemenin daha iyi özelliklere sahip numuneler elde edilmesini sağlayacağını ifade etmişlerdir [10].

Özdemir ve diğ. 2010'da yapmış oldukları çalışmada \%99 yoğunluktaki NiAl bileșiğini basınç destekli yanma sentez ile başarılı bir şekilde üretilebileceğini, göreceli yoğunluğunun \%99.6 ve NiAl malzemelerin oksidasyon aktivasyon enerjisi $156 \mathrm{~kJ} /$ mol olduğu sonucuna varmışlardır[11].

Čapek ve diğ. 2013'te NiTi numunelerini element tozlardan kendi kendine ilerleyen yüksek sicaklık sentezlenmesinin termal patlama modu metoduyla hazırlamışlardır. Yapmış oldukları bu çalışma sonucunda sinterlemenin süresinin; mikroyapı, sertlik ve dönüşüm davranışlarını etkilediğini, sinterleme süresi ve basınç davranışları arasında bir ilișkinin bulunmadığını ifade etmişlerdir [12].

Yapılan literatür araștırması sonucunda kendi kendine ilerleyen yüksek sıcaklık sentezlemesi (KKIYSS) tekniği ile $\mathrm{Ni}_{3} \mathrm{Al} / \mathrm{NiAl} / \mathrm{NiTi}$ bileșiklerinden oluşan fonksiyonel derecelenmiş malzeme (FDM) üretimine ilişkin yeterli bilginin ortaya konulamamıș olduğu görülmüștür. $\mathrm{Bu}$ nedenle bu çalışmada, ön ısıtma sıcaklığının KKIYSS yöntemiyle üretilen fonksiyonel derecelendirilmiș $\mathrm{Ni}_{3} \mathrm{Al} / \mathrm{NiAl} / \mathrm{NiTi}$ intermetalik bileşiğinin mikro ve makro yapısına etkilerinin belirlenmesi amaçlanmıştır

\section{Materyal ve Yöntem}

\subsection{Deneylerde Kullanılan Malzemeler}

$\mathrm{Bu}$ çalışmada kullanılan tozların ortalama büyüklüğü -325 mesh'tir. Malzemelerin başlıca özellikleri, Tablo 1'de verilmiștir.

İntermetalik FDM'lerin üretiminde kullanılan nikel, titanyum ve alüminyum tozları Elista Kimya Ltd. Sirketi aracılığıyla (\% 99.5 saflıkta Ni, \% 99.5 saflıkta Al ve \%99.5 Ti) yurt dışından Alfa Aesar firmasından tedarik edildi.

Tablo 1: Bir tablo örneği.

\begin{tabular}{|c|c|c|c|c|c|c|}
\hline 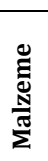 & $\begin{array}{c}\text { Ağırlıkç } \\
\text { a saflık } \\
\text { derecesi } \\
(\%)\end{array}$ & $\begin{array}{c}\text { Toz } \\
\text { Boyutu } \\
\text { (mesh) }\end{array}$ & $\begin{array}{c}\text { Erime } \\
\text { Sicaklığ } 1 \\
\left({ }^{\circ} \mathrm{C}\right)\end{array}$ & $\begin{array}{c}\text { Özgül } \\
\text { Ağırlık } \\
\left(\mathrm{gr} / \mathrm{cm}^{3}\right)\end{array}$ & $\begin{array}{c}\text { Atom } \\
\text { Kütlesi } \\
\text { (gr/mol) }\end{array}$ & $\begin{array}{c}\text { Kaynama } \\
\text { Sıcaklığı. } \\
\left({ }^{\circ} \mathrm{C}\right)\end{array}$ \\
\hline $\mathrm{Ni}$ & 99.5 & -325 & 1453 & 8.908 & 58.71 & 2832 \\
\hline$\overline{A l}$ & 99.5 & -325 & 660.4 & 2.7 & 26.9 & 10.81 \\
\hline Ti & 99.5 & -325 & 1680 & 4.507 & 47.9 & 3260 \\
\hline
\end{tabular}

\subsection{Deneysel Yöntem}

Üretim ișleminden önce, ticari olarak temin edilen $\mathrm{Ni}-\mathrm{Al}, \mathrm{Ni}_{3}-\mathrm{Al}$ ve Ni-Ti tozları atomik ağırlıkları göz önüne alınarak hassas terazide tartıldıktan sonra farklı kaplar içerisinde, homojen bir karıșım sağlamak için özel olarak tasarlanan dönen bir kap içerisinde 16 devir/dakika ile 24 saat süreyle karıştırıldı. Karıștırılan tozlar $12 \mathrm{~mm}$ çapında silindir şeklinde önceden hazırlanmış olan çelik bir toz kompaktlama kalıbı içerisinde $200 \mathrm{MPa}$ basınç altında soğuk preslendi.

Preslenen parçaların ön ısıtmalarını ve ateşleme işlemini gerçekleştirmek amacıyla tasarımı ve imalatı tarafımızdan gerçekleștirilmiș 40×40×30 mm boyutlarında manuel kontrollü bir ateşleme ünitesi kullanılmıştır. $\mathrm{Bu}$ ateşleme ünitesi düzeneği beș ana bileșenden olușmaktadır. Bunlar; ön ısıtma odacı̆̆l, ateșleme merkezi ve haznesi, sabitleme pistonu, sıcaklık ayar düğmesi ve argon gazı giriş ve çıkış bölümleridir. Preslenmiş numuneler, ateşleme ünitesinde 200,300 ve $400{ }^{\circ} \mathrm{C}$ ön tavlama sıcaklıklarında tavlandıktan sonra, argon gazı ortamında SHS yöntemi kullanılarak numuneler ateşlendi. Ateşleme sonrası elde edilmiş olan numune Şekil 1'de gösterilmiştir.

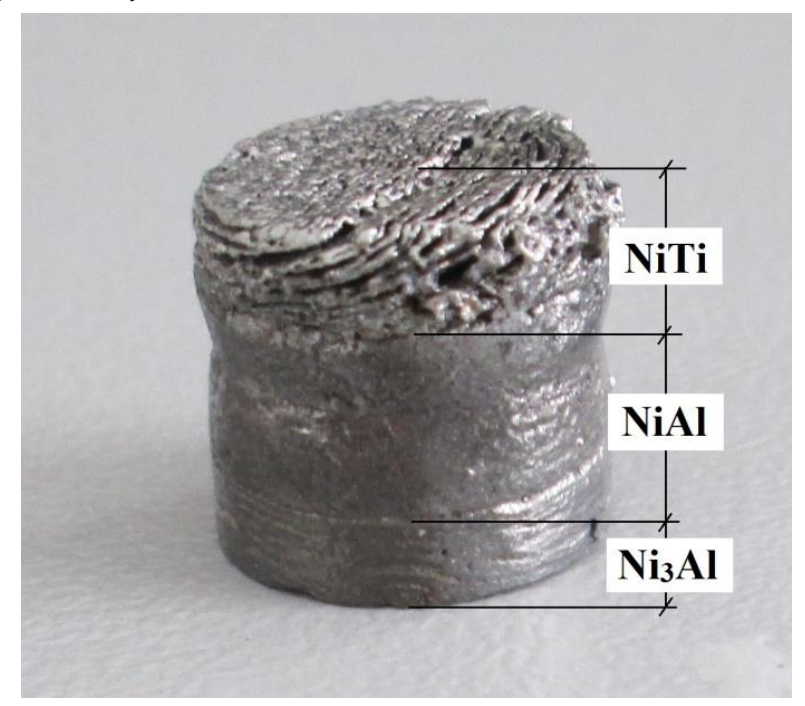

Şekil 1: Parçaların presleme şekli ve ateşleme sonrası elde edilen numunenin fotoğrafi.

Ateșleme sonrası numuneler kesildikten sonra faklı boyutlardaki zımparalar ile parlatma ve akabinde dağlama ișlemlerine tabii tutulmuștur. Elde edilen ürünlerin ana bölgeler ve ara bölgelerinde oluşan faz ve bileşikleri tespit etmek amacıyla BRUKER marka XRD-6000 cihazıyla $\mathrm{Cu}$ tüp/Ko X-Ișını tüpü, dalga boyu $(\lambda=1.54056 \AA), 40 \mathrm{kV}, 40 \mathrm{~mA}$ kullanılarak X-Işını kırınım (XRD) analizleri yapılmıştır. XRD analiz sonuçları daha önce bu cihaz ile yapılmıș çalıșmaların sonuçlarıyla karşılaştırılarak tespit edilmiştir. Ayrıca ateşleme sonrası elde edilen numunelerde oluşan faz ve yapılar tespit etmek için LEO marka EVO 40 VP model SEM cihazı ve BRUKER $125 \mathrm{eV}$ marka EDS analiz test cihazı kullanılarak belirlenmiştir.

\section{Sonuç ve Tartışma}

\subsection{Mikroyapı İncelemeleri}

$200 \mathrm{MPa}$ presleme basıncı ve 200,300 ve $400{ }^{\circ} \mathrm{C}$ 'lik ön ısıtma sıcaklıklarında üretilen numunelerin makro fotoğraflarından 
sentezleme işleminin gerçekleştiği görülmektedir. Ancak sadece $200^{\circ} C^{\prime}$ lik ön ısıtma sıcaklığında numune bütünlüğünün korunduğu tespit edildi. 300 ve $400{ }^{\circ} \mathrm{C}^{\prime}$ lik ön isitma sıcaklıklarındaki numunelerin özellikle $\mathrm{NiTi}$ ve NiTi-Ni${ }_{3} \mathrm{Al}$ bölgelerinde şekil bütünlüğünün kaybolduğu özellikle $400^{\circ} \mathrm{C}$ 'lik ön ısıtma sıcaklıklarında bunun arttığı görülmektedir. $400^{\circ} \mathrm{C}$ 'lik ön ısıtma sıcaklığındaki bu şekil bozukluğunun artan ön ısıtmayla artmış olduğu şekilde de görülmektedir (Şekil 2, 3 ve 4). Ancak yine de, 200 ve $400{ }^{\circ} \mathrm{C}^{\prime}$ lik ön isıtma sıcaklıklarındaki numunelerin her iki ara bölgelerinde de geniş yanma olukları gözlemlenirken $300{ }^{\circ} \mathrm{C}$ 'lik ön ısıtma sıcaklığındaki numunenin sadece NiTi-NiAl ara bölgesinde meydana geldiği görüldü. Sentezlenen numunenin ana malzemeler ve ara yüzeylerinden alınan optik mikroyapı fotoğraflarından ara kesitler dışında sadece $200{ }^{\circ} \mathrm{C}$ 'lik ön isıtma sıcaklığında gözeneklerin oluştuğu görülmüştür. $300^{\circ} \mathrm{C}$ 'lik ön ısıtma sıcaklıklarında ise özellikle $\mathrm{NiAl}$ ve Ni3Al bölgelerinde gözenekler daha yoğundur. Düşük ön ısıtma sıcaklıkları kullanıldığı zaman ya sıvı oluşumu gerçekleşmez ya da oluşan sıvının miktarı çok düşüktür. Düşük ön ısıtma sıcaklığında $\left(200^{\circ} \mathrm{C}\right)$ ergime gerçekleşmediğinden yoğunluğu daha düşük ve daha fazla gözeneğe sahip malzemeler elde edilir. Ön ısıtma sıcaklığı belli bir değerde (300 ${ }^{\circ} \mathrm{C}$ gibi) olduğu zaman reaksiyon sırasında oluşan sıvı miktarı ve ergime artar [13].
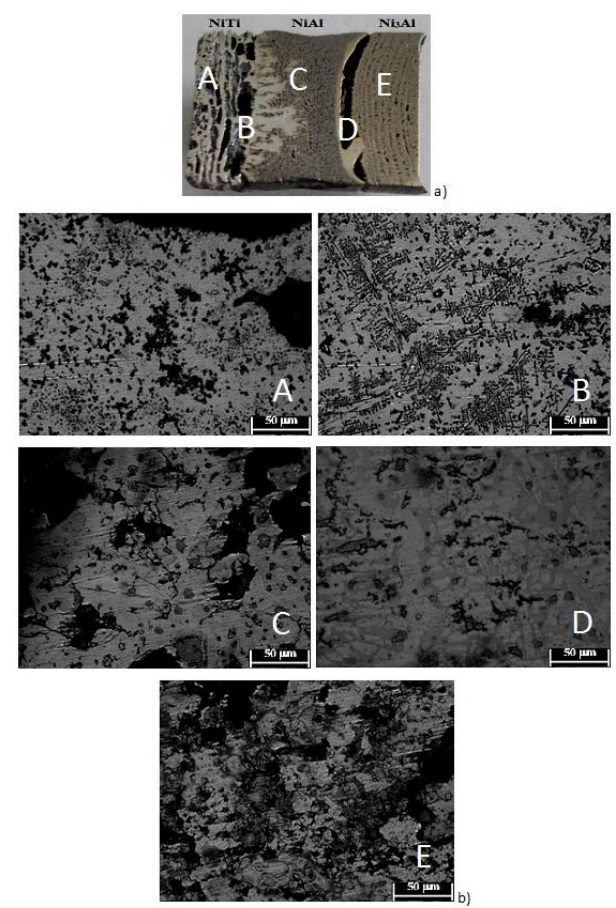

Şekil 2: a) Kompaktlama basıncı: $200 \mathrm{MPa}$,

Ön ısıtma Sıc.: $200^{\circ} \mathrm{C}$ numuneye ait makro yüzey fotoğrafı

b) Optik mikroskop görüntüleri.

Üç ön ısıtma sıcaklığına ait optik fotoğraflardan da görüldüğü gibi NiTi - NiAl ara kesitlerinde yoğun dentritik oluşumlar gözlemlenmiştir. Ham kompaktlardaki orijinal gözenekler dolayısıyla nihai ürünlerde elde edilen gözeneklerin ana kökenidir [14].

Michalski ve diğ., 2006, kendi kendine yayılan yüksek sıcaklık sentezi ile üretilen malzemelerin önemli bir dezavantajının, yüksek gözeneklilik olduğunu ifade etmiştir[15].

Gözenek oluşumunda; ham gözeneklilik, ön ısıtma sıcaklığı, reaksiyon sırasında gaz oluşumu, termal göç, reaksiyona giren maddelerin hacim küçülmesi ve Ni-Ti arasındaki difüzyon farkı etkilidir. $1173 \mathrm{~K}$ sıcaklıktaki $\mathrm{Ni}$ atomlarının Ti atomları içerisindeki difüzyon hızı, $\mathrm{Ti}$ atomlarının $\mathrm{Ni}$ atomları içerisindeki difüzyon hızına göre 4000 kat fazladır. Gazın bir kısmı çıkarken, dış basınç arttığından dolayı bir kısmı da içeride hapsedilir. Ayrıca alaşım oluşurken büzülmeler de olur. Büzülmeler esnasında da içeri gaz sızıp hapsolabilir. Böylece kapalı gözenekler, küçük odacıklar oluşur. Büzülmeler tam olarak kapanmadığı zaman odacıklar dar geçitlerle birbirlerine veya kanallara açılır. Böylece küçük açık gözenekler oluşur. Gözeneklerin şekilleri değişik biçimlerde oluşabilmektedir [16].

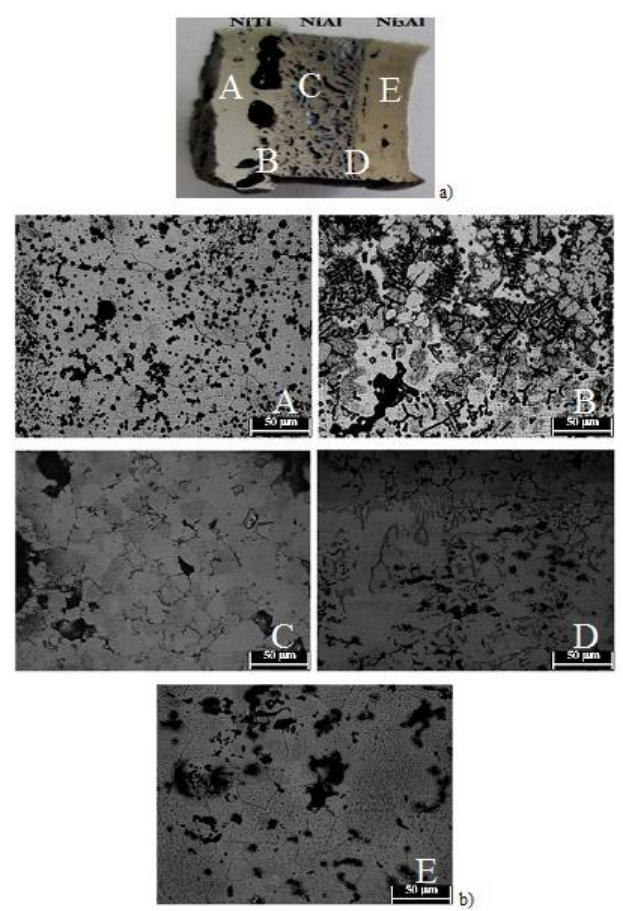

Şekil 3: a) Kompaktlama basıncı: $200 \mathrm{MPa}$,

Ön ısıtma Sıc: $300^{\circ} \mathrm{C}$ numuneye ait makro yüzey fotoğrafı b) Optik mikroskop görüntüleri

\subsection{SEM ve EDS İncelemeleri}

$200 \mathrm{MPa}$ basınç altında preslenerek $200{ }^{\circ} \mathrm{C}^{\prime}$ lik ön isıtma sıcaklığı kullanılarak sentezlenen numuneden alınan SEM fotoğrafları ve EDS analizleri Şekil 5 ve 6' da görülmektedir. $\mathrm{NiTi}$ ve NiTi-NiAl ara bölgesinden alınan EDS analizleri sonucunda NiTi kısmında \%45 Ni, \%55 Ti değerleri elde edilmiş ayrıca NiTi-NiAl ara bölgesinde de \%45 Ni, \%55 Ti elde edilmiştir. Elde edilen değerler Ni-Ti ikili denge diyagramı yardımıyla değerlendirildiğinde ve XRD sonucundan NiTi tarafında ve ara bölgede $\mathrm{NiTi}+\mathrm{Ti}_{2} \mathrm{Ni}$ intermetalik fazının meydana geldiği görüldü. NiAl tarafından alınan EDS sonucunda \%53 Al, \%47 Ni değeri elde edildi. Ni-Al ikili denge diyagramı yardımıyla bu bileşimin AlNi fazının bileşimi ile uyuștuğu görülmektedir. $\mathrm{NiAl}$ ve $\mathrm{Ni}_{3} \mathrm{Al}$ ara bölge kısmından alınan EDS sonuçlarından \%26Al ve \%74 Ni değerleri elde edilmiş ve bu yapının Al-Ni ikili denge diyagramı yardımıyla $\mathrm{Ni}_{3} \mathrm{Al}$ intermetalik fazına işaret ettiği sonucu ortaya çlkmıștır. $\mathrm{Ni} 3 \mathrm{Al}$ kısmından alınan EDS sonuçlarından \%13 $\mathrm{Al}$ ve \%87 $\mathrm{Ni}$ değerleri elde edildi ve bu yapının Al-Ni ikili denge diyagramı yardımıyla $\alpha \mathrm{Ni}+\mathrm{AlNi}_{3}$ intermetalik fazına işaret ettiği sonucuna varıldı. 


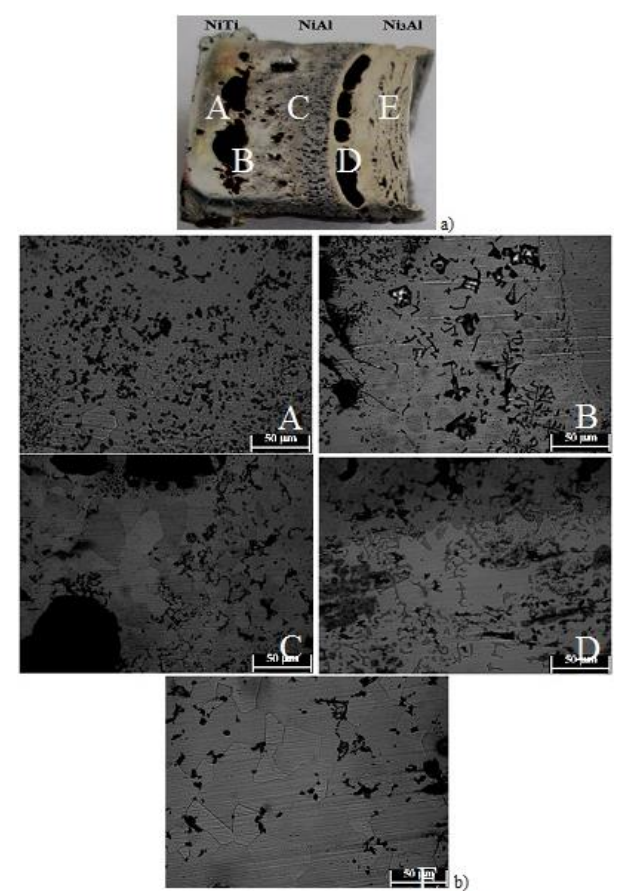

Şekil 4: a) Kompaktlama basıncı: $200 \mathrm{MPa}$, Ön ısıtma Sıc: $400{ }^{\circ} \mathrm{C}$ numuneye ait makro yüzey fotoğrafı b) Optik mikroskop görüntüleri.

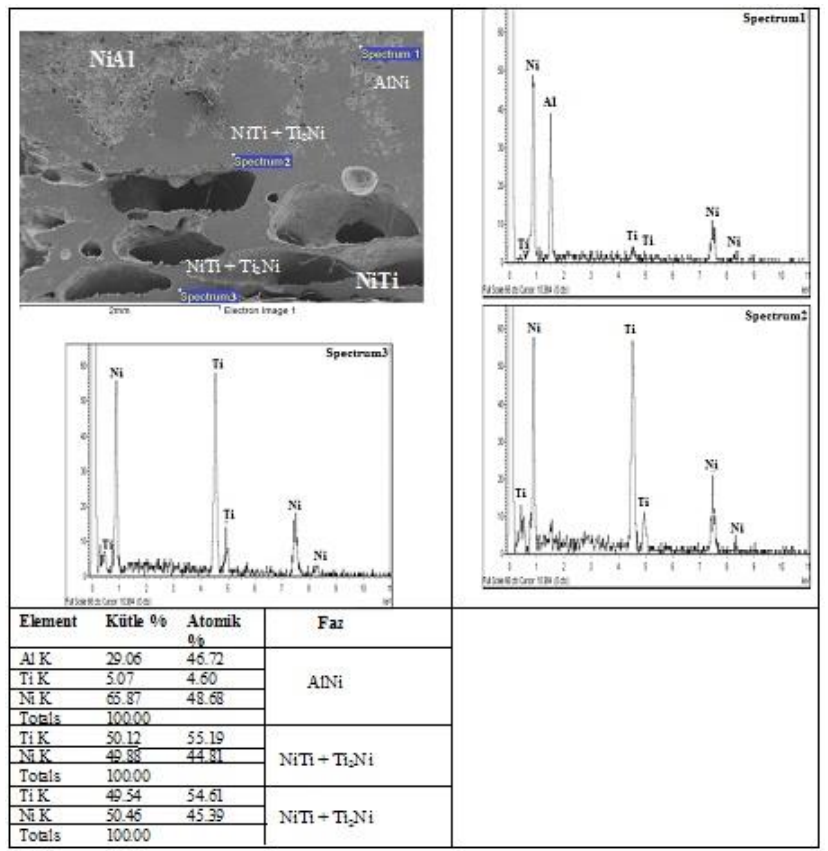

Sekil 5: $200 \mathrm{MPa}$ kompaktlama basıncı ve $200^{\circ} \mathrm{C}$ ön ısıtma sıcaklığına sahip numuneye ait SEM fotoğrafı ve EDS sonuçları. Kompaktlama basıncı $200 \mathrm{MPa}$ ve ön ısıtma sıcaklıkları 300 ve 400 olan numunelerin SEM ve EDS analiz sonuçları Șekil 7, 8, 9 ve 10' da sirasıyla gösterilmektedir. Bu numunelere ait sonuçlara incelendiğinde ana fazlarla birlikte farklı fazların yer aldığı analiz sonuçlarında yer almaktadır.

\subsection{XRD Analizi}

$200 \mathrm{MPa}$ presleme basıncı kullanılarak üretilen numunelerde yapılan XRD analizleri sırasıyla (Şekil 11, 12 ve 13) NiTi, NiAl ve $\mathrm{Ni}_{3} \mathrm{Al}$ fazlarıyla birlikte $\mathrm{Al}_{3} \mathrm{Ti}$ ve $\mathrm{TiAl}_{3}$ fazlarının bulunduğu göstermiștir. Yeh ve diğ. 2004'te yapmıș oldukları bir çalışmada, XRD analizi sonucunda $\mathrm{NiTi}, \mathrm{NiTi}_{2}, \mathrm{Ni}_{3} \mathrm{Ti}$ ve $\mathrm{Ni}_{4} \mathrm{Ti}_{3}$ dâhil olmak üzere çok sayıda fazın yanı sıra gözenekli nihai ürün ve reaksiyona girmemiş Ni'in de yapıda bulunduğu tespit edildi. Bununla birlikte, reaksiyona girmemiş Ni miktarının büyük ölçüde azalmıș olduğunu ve baskın olan bileșik NiTi miktarının yoğun ürünlerde önemli ölçüde artmış olduğunu tespit etmişlerdir. Yeh ve diğ, 2004 baskın faz NiTi, diğer iki sabit fazın ise $\mathrm{NiTi}_{2}$ ve $\mathrm{Ni}_{3} \mathrm{Ti}$, belirtmiş ve aynı zamanda 3-7 $\mu \mathrm{m}$ Ni tozu kullanılan ürünlerde olduğunu ifade etmişlerdir [17]. $\mathrm{Bu}$ çalıșmada NiTi fazının oluștuğu XRD analizleriyle gösterilmiştir; diğer fazların oluşumu ise EDS analiz sonuçlarına göre ortaya konmuştur. Dong ve diğ. sıcaklık 540 ${ }^{\circ} \mathrm{C}$ 'den itibaren yükseldikçe, $\mathrm{Al}$ pikinin azaldığından ve $\mathrm{NiAl}$ ve $\mathrm{Ni3Al,} \mathrm{Ni2Al3'ün} \mathrm{oluşumu} \mathrm{ile} \mathrm{ilgili} \mathrm{noktaların} \mathrm{varlığından} \mathrm{söz}$ etmișlerdir [18]

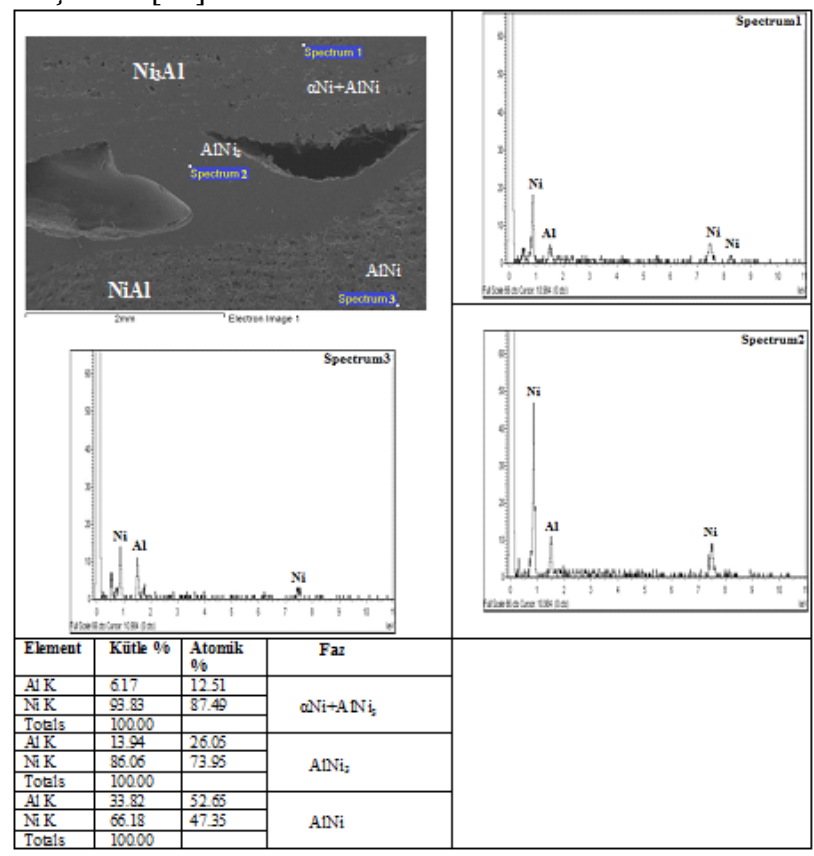

Şekil 6: $200 \mathrm{MPa}$ kompaktlama basıncı ve $200{ }^{\circ} \mathrm{C}$ ön ısıtma sıcaklığına sahip numuneye ait SEM fotoğrafı ve EDS sonuçları.

\section{Sonuç}

1) Sonuçlardan, üç farklı toz karışımının tek kalıpta preslenerek sentezlenmesiyle tek parça fonksiyonel bir malzemenin başarıyla üretilebileceği görüldü.

2) $200 \mathrm{MPa}$ presleme basıncı ve 200,300 ve $400^{\circ} \mathrm{C}^{\prime}$ lik ön ısıtma sıcaklıklarında üretilen numunelerin makro fotoğraflarından sentezleme işleminin başarıyla gerçekleștiği ve sadece $200^{\circ} C^{\prime}$ lik ön isıtma sıcaklığında numune bütünlüğünün korunduğu görüldü.

3) Sentezlenen numunenin ana malzemeler ve ara yüzeylerinden alınan optik mikroyapı fotoğraflarından ara kesitler dışında sadece $200^{\circ} \mathrm{C}^{\prime}$ lik ön isıtma sıcaklığında gözeneklerin oluștuğu görülmüștür. 300 ve $400^{\circ} \mathrm{C}^{\prime}$ lik ön ısıtma sıcaklıklarında ise özellikle $\mathrm{NiAl}$ ve $\mathrm{Ni}_{3} \mathrm{Al}$ bölgelerinde gözeneklerin daha yoğun olduğu tespit edildi.

4) Optik mikroyapı fotoğraflarından NiTi-NiAl ara kesitinde dentritik oluşum gözlemlenmiştir. Artan ön ısıtma sıcaklığı ile birlikte ara bölgelerde geniş yanma holleri meydana geldiği gözlendi. 


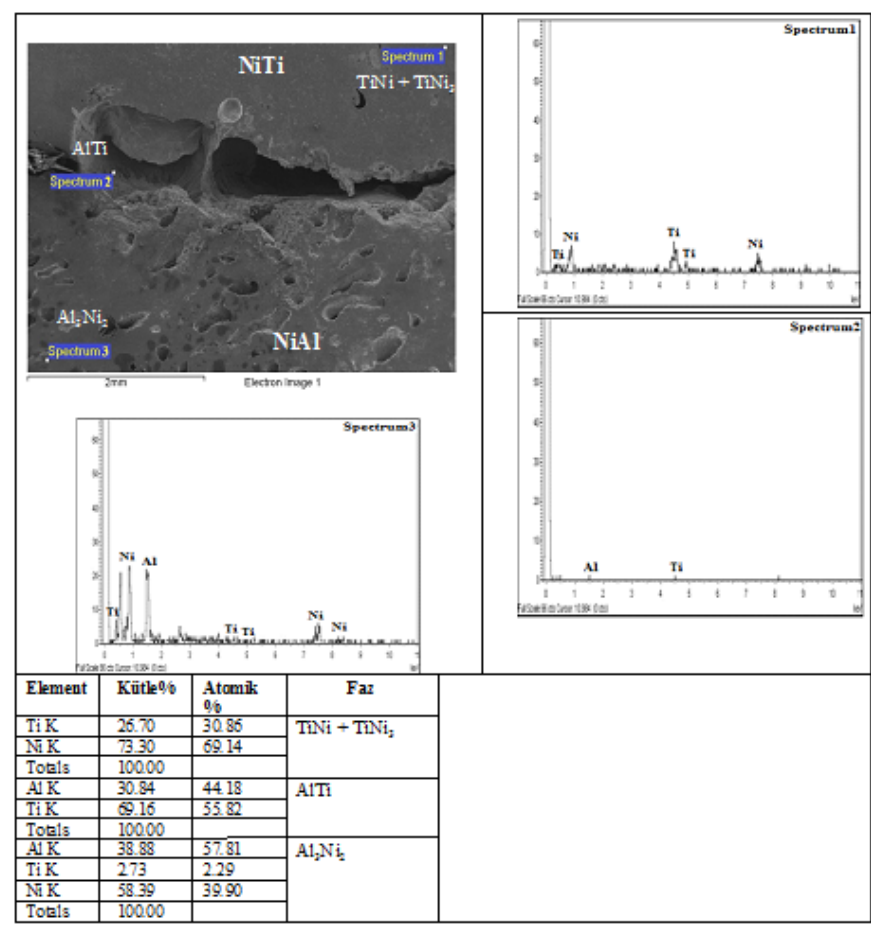

Șekil 7: $200 \mathrm{MPa}$ kompaktlama basıncı ve $300^{\circ} \mathrm{C}$ ön ısıtma sıcaklığına sahip numuneye ait SEM fotoğrafı ve EDS sonuçları.

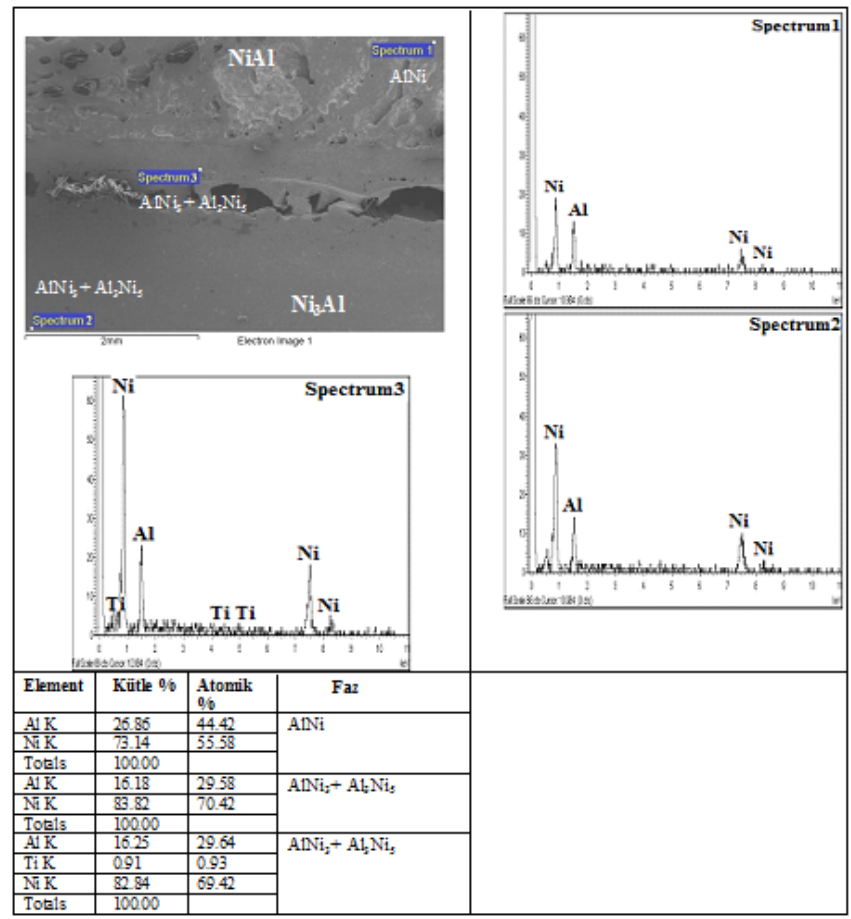

Şekil 8: $200 \mathrm{MPa}$ kompaktlama basıncı ve $300{ }^{\circ} \mathrm{C}$ ön ısıtma sıcaklığına sahip numuneye ait SEM fotoğrafı ve EDS sonuçları.

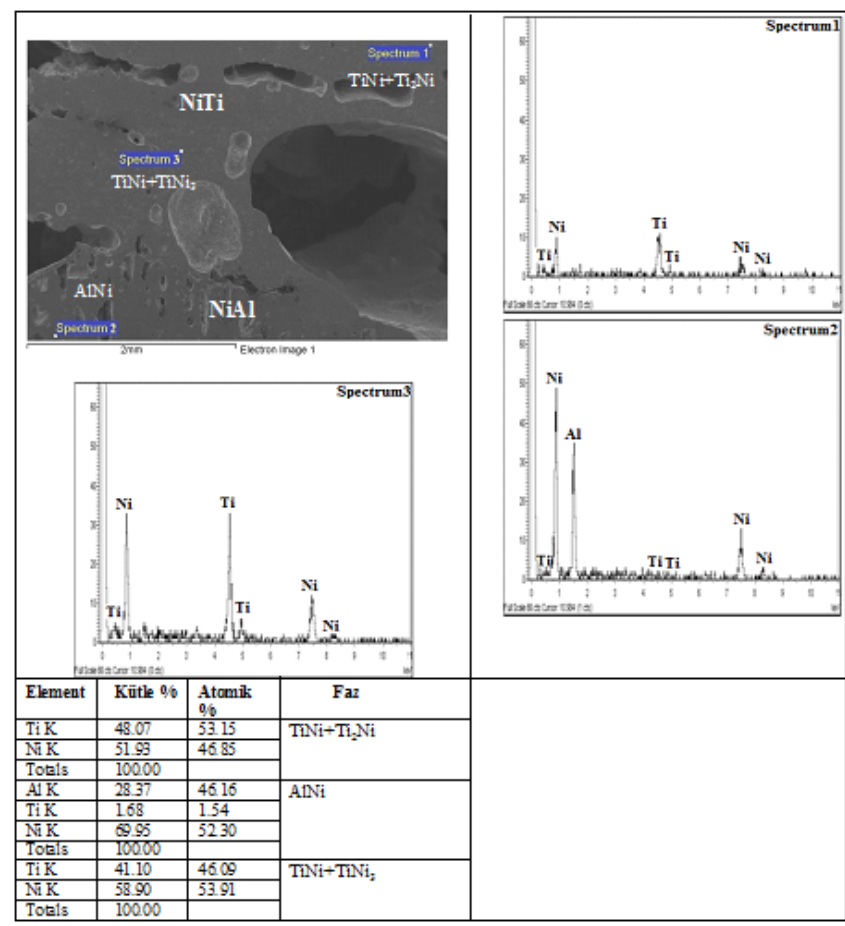

Şekil 9: $200 \mathrm{MPa}$ kompaktlama basıncı ve $400{ }^{\circ} \mathrm{C}$ ön ısıtma sıcaklığına sahip numuneye ait SEM fotoğrafı ve EDS sonuçları.

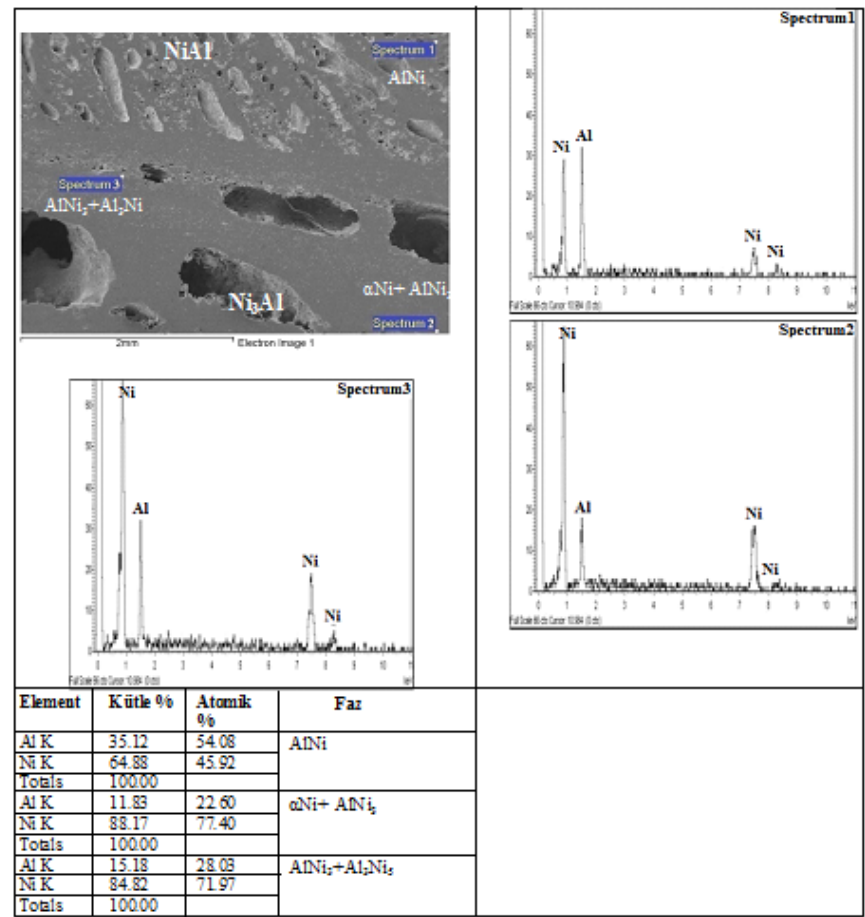

Şekil 10: $200 \mathrm{MPa}$ kompaktlama basıncı ve $400^{\circ} \mathrm{C}$ ön Isıtma sıcaklığına sahip numuneye ait SEM fotoğrafı ve EDS sonuçları. 


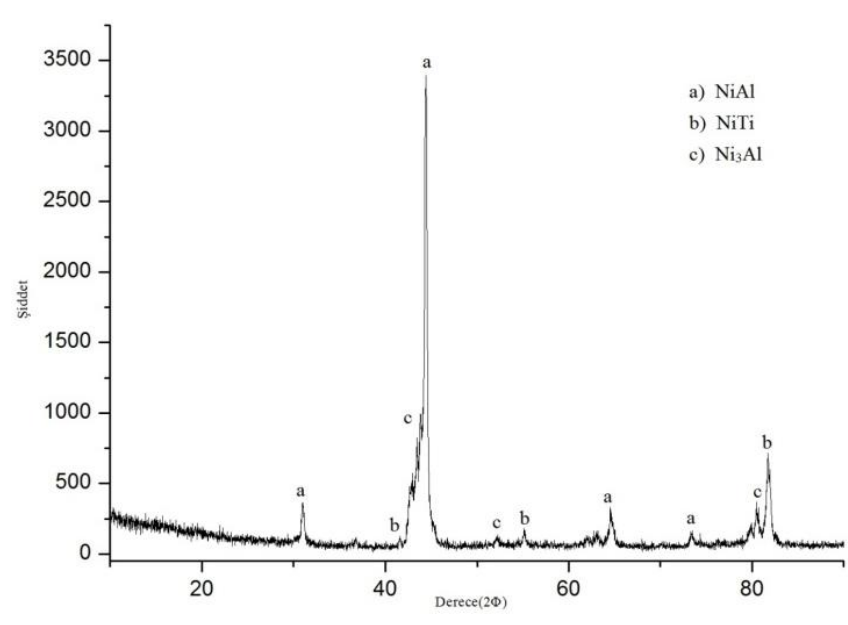

Şekil 11: $200 \mathrm{MPa}$ kompaktlama basıncı ve $200{ }^{\circ} \mathrm{C}$ ön ısıtma sıcaklığına sahip numuneye ait XRD paterni.

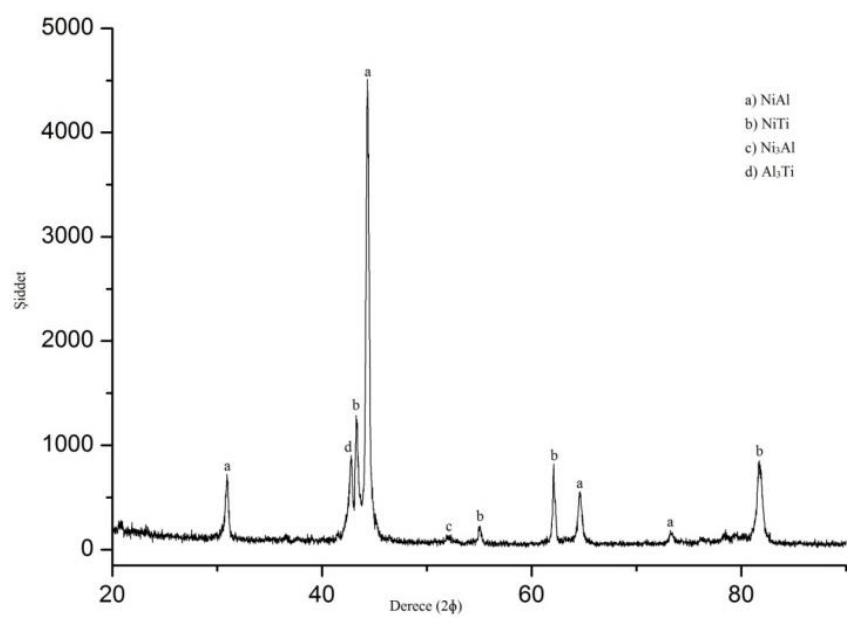

Şekil 12: $200 \mathrm{MPa}$ kompaktlama basıncı ve $300^{\circ} \mathrm{C}$ ön ısıtma sıcaklığına sahip numuneye ait XRD paterni.

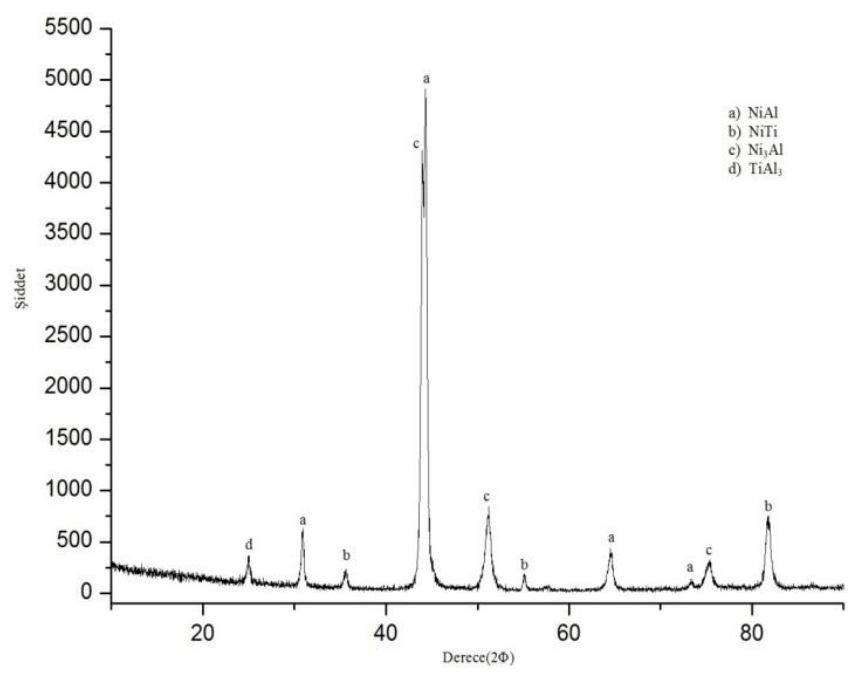

Şekil 13: $200 \mathrm{MPa}$ kompaktlama basıncı ve $400{ }^{\circ} \mathrm{C}$ ön ısıtma sicaklığına sahip numuneye ait XRD paterni.

5) $200 \mathrm{MPa}$ kompaktlama basıncı ve 200,300 ve $400{ }^{\circ} \mathrm{C}$ 'lik ön ısıtma sicaklıklarına sahip numunelerin XRD analiz sonuçlarında, $200^{\circ} \mathrm{C}^{\prime}$ lik ön isıtma sıcaklığına sahip numunede
Ti, NiAl ve $\mathrm{Ni}_{3} \mathrm{Al}$ ana fazlarının oluștuğu 300 ve $400{ }^{\circ} \mathrm{C}^{\prime}$ lik ön ısıtma sıcaklıklarına sahip numunelerde ise ana fazlarla birlikte $\mathrm{TiAl}_{3}$ fazının oluştuğu tespit edildi

\section{Teşekkür}

19.02.2015 tarihinde vefat eden değerli hocam Prof.Dr. Nuri Orhan'a Allah'tan rahmet dilerim. FUBAP-TEKF.13.02 no.lu proje kapsamında gerçekleștirilmiş olan bu çalışmaya destek vermiş olan Fırat Üniversitesi Rektörlügü'ne yazarlar olarak teşekkür ederiz. Pamukkale Üniversitesi Mühendislik Bilimleri Dergisine katkı sağlayan tüm yazar ve hakemlere teşekkür ederiz.

\section{Kaynaklar}

[1] Koizumi M. "FGM Activities in Japan". Composites Part B: Engineering, 28(1-2), 1-4, 1997.

[2] Kieback B, Neubrand A, Riedel H. "Processing Techniques for Functionally Graded Materials". Materials Science and Engineering: A, 362(1-2), 81-106, 2003.

[3] Sobczak JJ, Drenchev L. "Metallic Functionally Graded Materials: A Specific Class of Advanced Composites". Journal of Materials Science \& Technology, 29(4), 297-316, 2013.

[4] Burkes DE, Moore JJ, "Microstructure and Kinetics of a Functionally Graded NiTi-TiCx Composite Produced by Combustion Synthesis". Journal of Alloys and Compounds, 430(1-2), 274-281, 2007.

[5] Mahamood RM, Esther TAM, Shukla M, Pityana S. "Functionally Graded Material: An overview". Proceedings of the World Congress on Engineering, London, United Kingdom, July, 4-6, 2012.

[6] Morris GD, Muñoz-Morris., MA. "Intermetallics: Past, Present and Future". Revista de Metalurgia, 41(Extr), 498-501, 2005

[7] Ergin N. Fe-Al İntermetalik Malzemenin Basınç Destekli Hacim Yanma Sentezi ile Üretimi ve Özelliklerinin İyileştirilmesi. Yüksek Lisans Tezi, Sakarya Üniversitesi, Sakarya, Türkiye, 2007.

[8] Rajan TPD, Pillai RM, Pai BC. "Functionally Graded Al$\mathrm{Al}_{3} \mathrm{Ni}$ in Situ Intermetallic Composites: Fabrication and Microstructural Characterization". Journal of Alloys and Compounds, 453(1-2), L4-L7, 2008.

[9] Zhang ML, Liu J, Yuan ZR, Hirai T. "Properties of TiC-Ni $\mathrm{N}_{3} \mathrm{Al}$ Composites and Structural Optimization of $\mathrm{TiC}-\mathrm{Ni}_{3} \mathrm{Al}$ Functionally Gradient Materials". Materials Science and Engineering 203(1-2), 272-277, 1995.

[10] Chen L, Jiandong H, Guo Z, Lou Q, Wang Z. "Ni-Al Functionally Graded Materials by Laser Self-Propagating High-Temperature Synthesis, Materials Transactions". Materials Transactions, 45(9), 2791-2793, 2004.

[11] Özdemir O, Zeytin S, Bindal C. "A Study on NiAl Produced by Pressure-Assisted Combustion Synthesis". Vacuum, 84(4), 430-437, 2010.

[12] Čapek J, Kučera V, Fousovà M, Vojtěch D. "Preparation Of the NiTi Shape Memory Alloy by the TE-SHS MethodInfluence of the Sintering Time". 22 ${ }^{\text {nd }}$ International Conference on Metallurgy and Materials, Brno, Czech Republic, 15-17 May 2013.

[13] Kaya M, Orhan N, Kurt B. "Gözenekli NiTi ŞHA'ın Toz Metalurjisi ile Üretimi ve Ön Isıtma Sıcaklığının Gözenek Oluşumu Üzerindeki Etkisi". Fırat Üniversitesi Doğu Anadolu Araştırmaları Dergisi, 23(4), 931-936, 2008. 
[14] Wisutmethangoon S, Denmud N, Sikong L. "Effect of Preheating Temperature and Chamber Pressure on the Properties of Porous NiTi Alloy Prepared by SHS Technique". World Academy of Science, Engineering and Technology, 68(1), 1694, 2012.

[15] Michalski A, Jaroszewicz J, Rosiński M, Siemiaszko D. "NiAl-Al2O3 Composites Produced by Pulse Plasma Sintering with the Participation of the SHS Reaction". Intermetallics, 14(6), 603-606, 2006.

[16] Kaya M. Toz Metalurjisi ile Üretilen NiTi Şekil Hatırlamalı Alaşımların Metalurjik ve Mekanik Karakteristiklerinin İncelenmesi. Doktora Tezi, Fırat Üniversitesi, Elazığ, Türkiye, 2008.
[17] Yeh CL, Sung WY. "Synthesis of NiTi Intermetallics by SelfPropagating Combustion". Journal of Alloys and Compounds, 376(1-2), 79-88, 2004.

[18] Dong HX, Jiang Y, He YH, Song M, Zou J, Xu NP, Huang BY, Liu CT, Liaw PK. "Formation of Porous Ni-Al Intermetallics Through Pressureless Reaction Synthesis". Journal of Alloys and Compounds, 484(1-2), 907-913, 2009.

[19] Kılıç M, Kırık İ, Kurt B, Orhan N. "Fonksiyonel Derecelendirilmiş $\mathrm{Ni}_{3} \mathrm{Al} / \mathrm{NiAl} / \mathrm{NiTi}$ İntermetalik Bileşiğine Ön Isıtma Sıcaklığının Etkisinin İncelenmesi”. 15th International Materials Symposium, Denizli, Turkey, 15-17 October 2014. 